\title{
Altered Spectrin Dimer-Dimer Association and Instability of Erythrocyte Membrane Skeletons in Hereditary Pyropoikilocytosis
}

\author{
Shih-Chun Liu, Jiri Palek, Joseph Prchal, and Richard P. Castleberry, \\ Departments of Research and Medicine, St. Elizabeth's Hospital and Tufts \\ University School of Medicine, Boston, Massachusetts 02135; Departments \\ of Medicine and Pediatrics, University of Alabama Medical School, Birmingham, \\ Alabama 35294
}

\begin{abstract}
A B S T RAC T Hereditary pyropoikilocytosis (HPP) is a hemolytic anemia characterized by microspherocytosis, poikilocytosis, and an unusual thermal sensitivity of erythrocytes. We have investigated the contribution of abnormal membrane skeletal assembly to these abnormal HPP erythrocyte properties. Skeletons prepared from fresh HPP ghosts with Triton X-100 were considerably more fragile than skeletons from control erythrocytes. Spectrin, the major skeleton component, extracted at $0^{\circ} \mathrm{C}$ from normal erythrocytes, was present primarily as tetramers and high molecular weight complexes. In contrast, spectrin extracted from HPP erythrocytes under identical conditions contained a significant amount of dimers with a concomitant decrease of tetramers. Furthermore, spectrin dimers from HPP erythrocytes differed from normal spectrin dimers in their failure to reassociate into tetramers both in solution and in the membrane. Presumptive HPP carriers (asymptomatic mothers of the two patients) exhibited a mild but reproducible increase of spectrin dimers in $0^{\circ} \mathrm{C}$ extracts and a defective reassociation of spectrin dimers of tetramers both in solution and in the membrane. We conclude that in HPP, self-association of spectrin dimers into tetramers is defective, which accounts for the instability of membrane skeletons.
\end{abstract}

This work was presented at the joint meetings of the 18th Congress of the International Society of Hematology and the 16th Congress of the International Society of Blood Transfusion Montreal, Canada, 18 August, 1980.

Received for publication 17 November 1970 and in revised form 5 May 1981.

\section{INTRODUCTION}

Hereditary pyropoikilocytosis (HPP) ${ }^{1}$ is a hemolytic anemia characterized by microspherocytosis, poikilocytosis, and an unusual thermal sensitivity of erythrocytes (1). Recently, several laboratories have reported abnormalities of the major membrane skeletal protein, spectrin, in HPP erythrocytes. Spectrin from these abnormal cells has an increased susceptibility to thermal denaturation, as measured by circular dichroism (2), extractability (3), and protein-protein cross-linking (4). Possible alterations of spectrin assembly in fresh HPP erythrocytes have not been previously described. In normal erythrocytes, the internal side of the membrane is laminated by fibers of spectrin dimers that form tetramers by head-to-head associations; the tetramers, in turn, are linked into a two-dimensional membrane skeleton by actin oligomers and polypeptide 4.1 (5-14). In this paper, we report that membrane skeletons from fresh HPP erythrocytes are markedly unstable and that this decreased skeletal stability is related to defective spectrin dimer-dimer association.

\section{METHODS}

Clinical material. Two patients from two unrelated Black families were studied. Both patients had a history of hemolytic anemia with splenomegaly since birth. Their major clinical and laboratory features were previously reported (4). At the time of this investigation, their ages were 9 (N.E.) and

\footnotetext{
${ }^{1}$ Abbreviations used in this paper: HPP, hereditary pyropoikilocytosis; HMW, high molecular weight complex; $\mathrm{Sp}-\mathrm{D}$, spectrin dimer; Sp-O, spectrin oligomer; Sp-T, spectrin tetramer.
} 
NORMAL
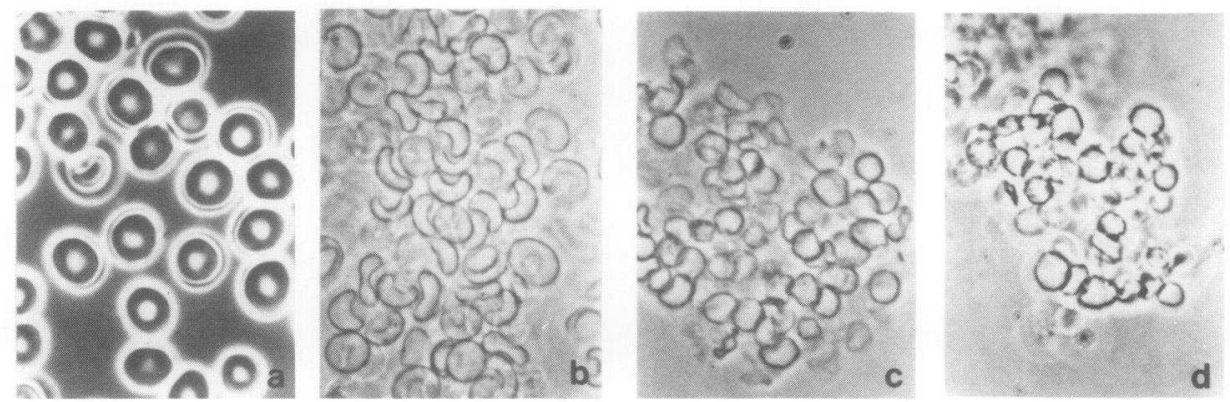

HPP PATIENT 1 (D.B.)
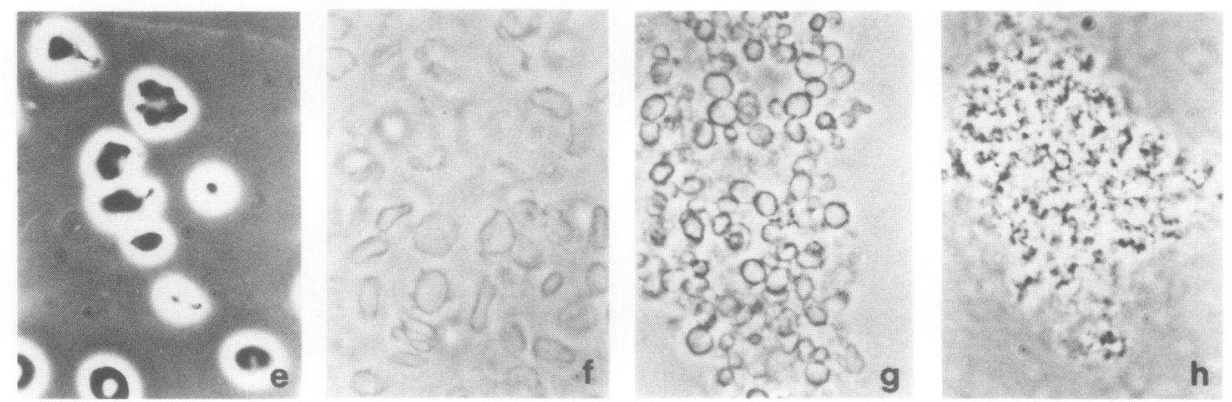

ASYMPTOMATIC MOTHER OF PATIENT 1 (E.B.)
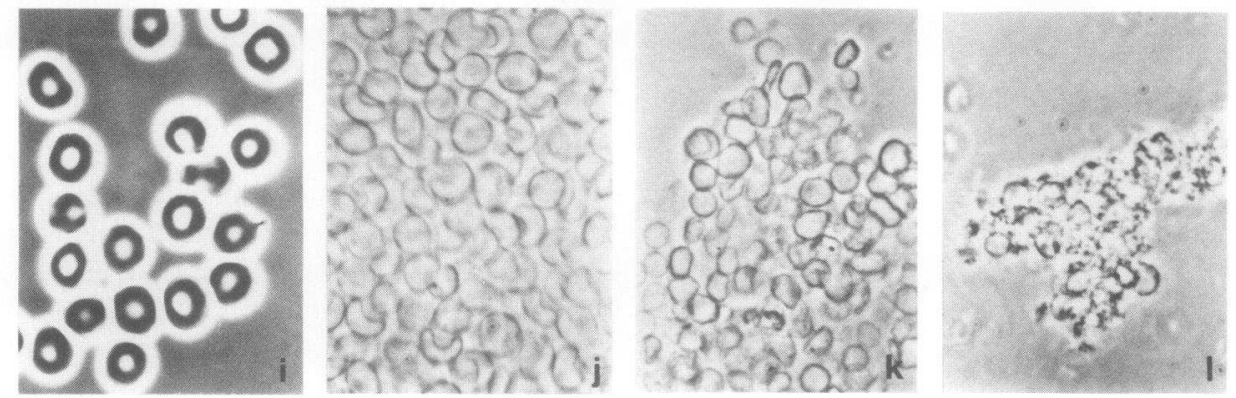

HPP PATIENT 2 (N.E.)

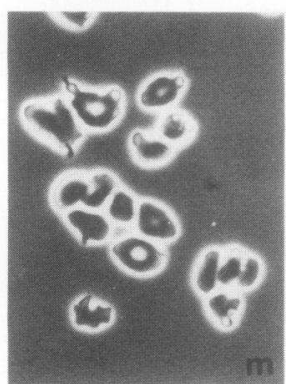

RBC

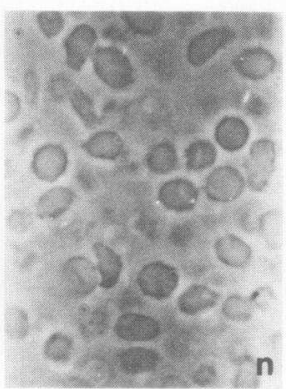

Ghosts

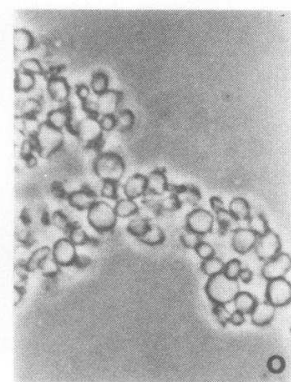

Membrane Skeletons

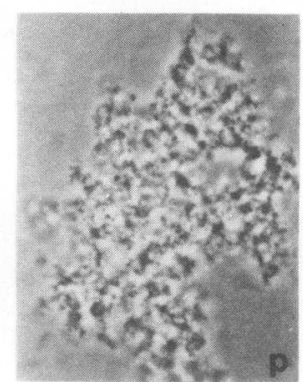

Mechanically Shaken Membrane Skeletons 
3 (D.B.) yr, respectively, and they both exhibited a moderate to severe hemolytic anemia, as detailed (4). The hemoglobin content ranged from 7.1 to $9.9 \mathrm{~g} / 100 \mathrm{ml}$ and reticulocyte count ranged from 5 to $24 \%$. The diagnosis of HPP was based on the characteristic erythrocyte morphology and increased susceptibility to thermal fragmentation and poikilocytosis (at $45^{\circ} \mathrm{C}$, whereas normal erythrocytes fragment at $49^{\circ} \mathrm{C}$ ). Patient N.E. was homozygous for hemoglobin C, whereas patient D.B. lacked identifiable hemoglobin abnormalities. Neither patient had evidence of abnormalities in glycolytic enzymes known to be associated with the nonspherocytic hemolytic anemia. None of the family members exhibited elliptocytosis. Venous blood from these patients was collected into sterile tubes containing citrate-phosphatedextrose, or anticoagulant-citrate-dextrose, put on ice, and transported in insulated containers from Birmingham, Ala., to Boston, where it was kept at $\sim 4^{\circ} \mathrm{C}$ and analyzed no later than $3 \mathrm{~d}$. A control sample was sent along each time.

Mechanical stability of membrane skeletons. Erythrocyte ghosts were prepared by the method of Dodge et al. (15). Morphology and mechanical stability of membrane skeletons were examined as described previously (7), except Triton extraction was carried out at $0^{\circ}$ instead of $25^{\circ} \mathrm{C}$ and skeletons were stained with $0.5 \%$ uranyl acetate.

Spectrin extraction. For low ionic strength extraction, erythrocyte ghosts were washed once with $0.1 \mathrm{mM} \mathrm{NaPO}$, pH 8.0, and immediately centrifuged to reduce the ionic strength of the medium and to obtain a smaller ghost pellet. Ghosts were then suspended in an equal volume of low ionic strength buffer containing $0.1 \mathrm{mM} \mathrm{NaPO}, 0.1 \mathrm{mM}$ EDTA, $0.1 \mathrm{mM}$ phenylmethylsulfonyl fluoride, $0.1 \mathrm{mM} \mathrm{N}-\alpha$ $p$-tosyl-L-lysine chloromethyl ketone $\mathrm{HCl}$, and $0.1 \mathrm{mM}$ mercaptoethanol, $\mathrm{pH}$ 8.0. After incubation at $0^{\circ} \mathrm{C}$ overnight or at $37^{\circ} \mathrm{C}$ for $20 \mathrm{~min}$, the supernatant extracts and ghost residues were separated by centrifugation at $250,000 \mathrm{~g}$ for $35 \mathrm{~min}$.

Protein electrophoresis. Sodium dodecyl sulfate (SDS) polyacrylamide gel electrophoresis of ghosts, extracted spectrin, and ghost residues was carried out with $5.6 \%$ polyacrylamide gels (16). To separate spectrin species by nondenaturing gel electrophoresis, the low ionic strength extracts $(\sim 15 \mu \mathrm{g}$ protein) were mixed with one-ninth volume of concentrated buffer to give a final solution containing $\mathbf{4 0}$ $\mathrm{mM}$ Tris- $\mathrm{HCl}, \mathrm{pH} 7.4,20 \mathrm{mM}$ Na acetate, $2 \mathrm{mM}$ dithiothreitol, $200 \mathrm{mM}$ sucrose, and $2 \mathrm{mM}$ EDTA, and electrophoresed in $0.3 \%$ agarose- $2.5 \%$ acrylamide gels as previously described (17), except that the temperature of electrophoresis was $2-6^{\circ} \mathrm{C}$ and SDS was omitted from the gels. In this gel system, spectrin tetramers $\left(M_{\mathrm{r}}=900,000\right)$ and dimers $\left(M_{\mathrm{r}}=450,000\right)$ have mobilities relative to bromophenol blue of about 0.13 and 0.23 , respectively.
Transformation of spectrin dimers to tetramers in solution. Spectrin dimers in the $37^{\circ} \mathrm{C}$ extract were tested for ability to reassociate into tetramers in solution by incubation of the extract $(0.4-0.8 \mathrm{mg} / \mathrm{ml})$ at $30^{\circ} \mathrm{C}$ under isotonic conditions (5 mM NaPO 4, pH 7.4, $150 \mathrm{mM} \mathrm{NaCl}, 1 \mathrm{mM}$ mercaptoethanol, $0.1 \mathrm{mM}$ phenylmethylsulfonyl fluoride, $0.1 \mathrm{mM} N-\alpha-p$ tosyl-L-lysine chloromethyl ketone $\mathrm{HCl}, 0.1 \mathrm{mM}$ EDTA) (5). The mixture was subsequently analyzed in nondenaturing agarose polyacrylamide gels.

Spectrin tetramer $\rightleftharpoons$ dimer transformation in the membrane. To induce spectrin tetramer-to-dimer transformation in the membrane, ghosts were incubated hypotonically at $37^{\circ} \mathrm{C}$ for $20 \mathrm{~min}$ in $\mathrm{NaPO}_{4}(5 \mathrm{mM})$ buffer containing $10 \mathrm{mM}$ $\mathrm{NaCl}, 0.1 \mathrm{mM}$ phenylmethylsulfonyl fluoride, $0.1 \mathrm{mM}$ $N$ - $\alpha$ - $p$-tosyl-L-lysine chloromethyl ketone $\mathrm{HCl}, 0.1 \mathrm{mM}$ EDTA, and $1 \mathrm{mM}$ mercaptoethanol. To reverse the transformation, ghosts were reincubated in isotonic buffer containing $150 \mathrm{mM} \mathrm{NaCl}$ for $20 \mathrm{~min}$ at $37^{\circ} \mathrm{C}$. Subsequently, crude spectrin was extracted $\left(0^{\circ} \mathrm{C}\right.$, overnight) from these ghosts and analyzed for spectrin species by nondenaturing gel electrophoresis.

\section{RESULTS}

Morphology and mechanical stability of membrane skeletons. Morphological studies of erythrocyte ghosts from the two HPP patients revealed that many ghosts retained the poikilocytic or microcytic shape of their precursors (Fig. 1, panel $f$ and $n$ ). When erythrocyte ghosts were extracted with Triton X-100 and then stained with uranyl acetate, HPP membrane skeletons (i.e., Triton-insoluble membrane residues) (Fig. 1, panels $g$ and o) appeared heterogeneous in size, and most of them were smaller than normal skeletons (Fig. 1 , panel c). Staining with uranyl acetate $(>0.5 \%)$ was required to enhance the contrast of membrane skeletons so that they might be visualized by phase-contrast light microscopy. The staining procedure, introduced artifacts of shrinkage and clumping of membrane skeletons (Fig. 1, panels c, g, k, o) in solution (7). These artifacts could be partially overcome by the use of a lower concentration of uranyl acetate $(0.05 \%)$. Although HPP membrane skeletons retained irregular shapes and heterogeneous sizes, they were only barely visible under these conditions (data not shown).

FIGURE 1 Morphology and mechanical stability of erythrocyte membrane skeletons. Erythrocytes and ghosts from normal individuals, two HPP patients, and asymptomatic mothers were examined by phase-contrast light microscopy without staining. Membrane skeletons were prepared by incubation of packed ghosts with 2 vol of Triton X-100 solution (3\% Triton X-100 in $5 \mathrm{mM} \mathrm{NaPO}, 1 \mathrm{mM}$ mercaptoethanol, $\mathrm{pH} \mathrm{7.4)}$ at $0^{\circ} \mathrm{C}$ for $30 \mathrm{~min}$. Aliquots $(200 \mu \mathrm{l})$ of skeleton suspensions from these three samples were transferred to small test tubes $(0.7 \times 7 \mathrm{~cm})$, mounted horizontally on a pipette shaker (Clay Adams, Div. of Becton, Dickinson \& Co., Parsippany, N. J. 1,550 oscillations/min) and examined morphologically before and after shaking (linear travel of $4 \mathrm{~mm} / \mathrm{oscillation})$ for $60 \mathrm{~min}$ at $2-6^{\circ} \mathrm{C}$. The membrane skeleton suspension $(5 \mu \mathrm{l})$ was taken out of the tube, applied onto a siliconized glass slide, gently mixed with $0.5 \%$ uranyl acetate $(5 \mu \mathrm{l})$, covered with a siliconized cover slip, and examined for skeleton fragmentation under the phase contrast light microscope. A gross disintegration (>95\%) of HPP membrane skeletons was noticed after shaking ( $h$ and $p)$, whereas those from the asymptomatic mothers were partially disintegrated (1) and those from normal individuals remained intact (d). 
Membranes

\section{Residues}

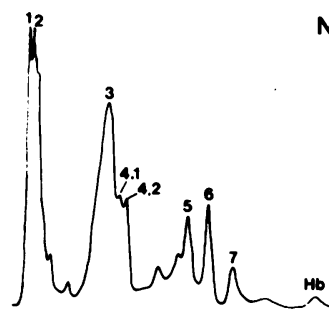

Normal
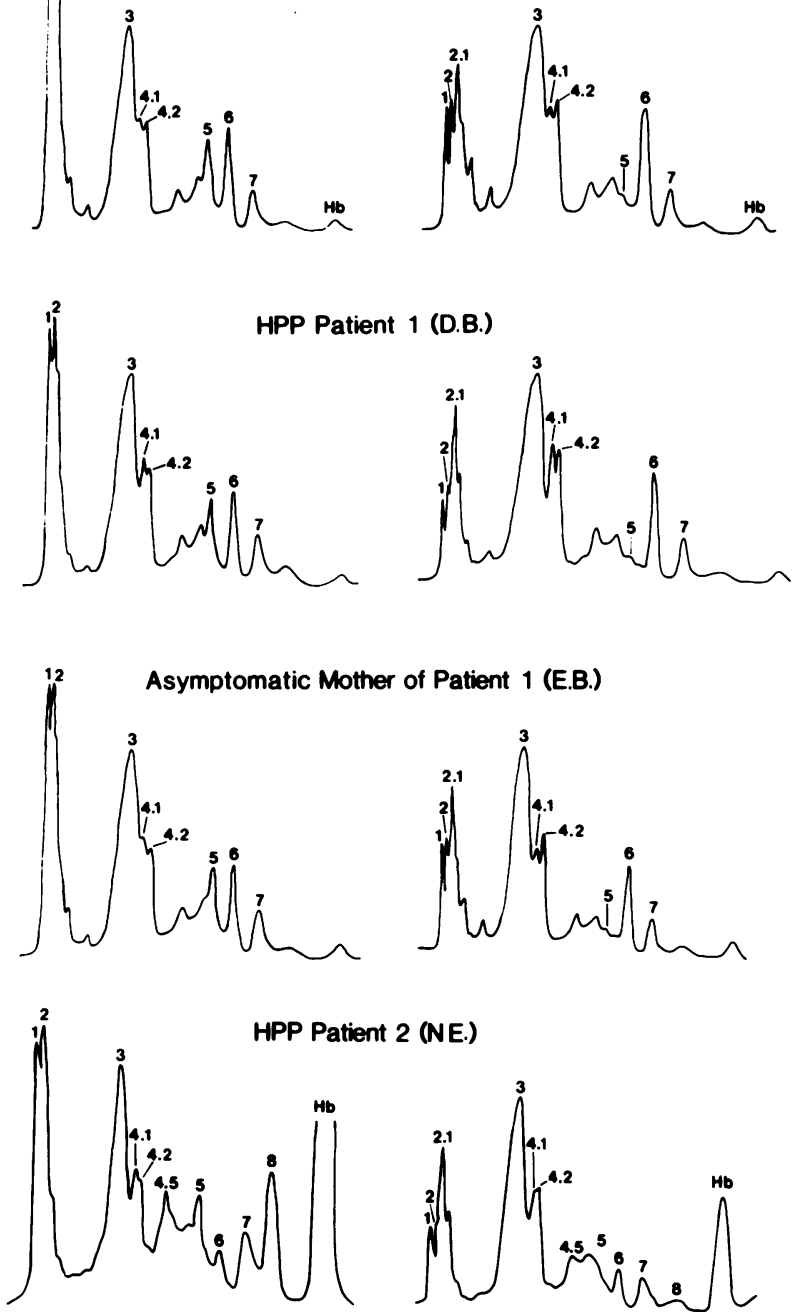

FIGURE 2 Polyacrylamide gel electrophoresis in SDS of ghosts and ghost residues after overnight extraction at $0^{\circ} \mathrm{C}$ in low ionic strength buffer. The efficiency of spectrin release was estimated from densitometric tracings before and after ghost extraction. A high efficiency of spectrin release $(85 \pm 5 \%)$ was noticed for samples from normal individuals, HPP patients, and the asymptomatic mother.

Membrane skeletons prepared by extraction of normal and HPP ghosts with Triton X-100 were enriched in spectrin, actin, and band 4.1 (data not shown). When subjected to mechanical shaking, membrane skeletons from both HPP patients were markedly unstable and disintegrated into fragments (Fig. 1, panels $h$ and $p$ ), whereas normal membrane skeletons remained mostly intact (Fig. 1, panel d). We have also examined membrane skeletons from the asymptomatic mothers of both HPP patients. Both mothers are hematologically normal in that they have normal morphology of erythrocytes, ghosts, and membrane skeletons (Fig. 1, panels $\mathrm{i}-\mathrm{k}$ ), and a normal thermal stability of their erythrocytes. Upon mechanical shaking, we observed a moderately but reproducibly decreased stability of membrane skeletons (Fig. 1, panel l).

Oligomeric states of spectrin in the membrane. Previous studies have shown that self-association of the major skeletal protein, spectrin, plays an important role in maintaining skeleton stability in normal erythrocytes (7). This is mainly because spectrin tetramers, but not dimers, can cross-link other skeletal components to form the two-dimensional network $(9-13)$. To investigate whether the self-association of spectrin is altered in HPP, which would account for skeletal instability, we examined the oligomeric state of spectrin extracted from HPP ghosts in low ionic strength buffer at $0^{\circ} \mathrm{C}$, a temperature at which spectrin is kinetically trapped in its native form (5). Fig. 2 compares the efficiency of spectrin extraction $\left(0^{\circ} \mathrm{C}\right.$, overnight) from ghosts of normal volunteers, HPP patients, and the asymptomatic mothers. The efficiencies of spectrin extraction from these samples were the same, i.e. $>85 \%$ of spectrin was released under these conditions. It was also noticed that the densitometric tracing of HPP membrane proteins did not differ from normal, with the exception of a slight decrease in spectrin-to-band 3 ratio (4) in both patients and an increase of bands $4.5,8$, and globin subunits in one of the HPP patients (N.E.).

The distribution of spectrin species in the crude spectrin extracted overnight at $0^{\circ} \mathrm{C}$ from erythrocyte ghosts were analyzed by nondenaturing gel electrophoresis. There were marked differences among normal erythrocytes, HPP erythrocytes, and erythrocytes from the asymptomatic mothers (Fig. 3A and B). The extract from normal erythrocytes contains principally spectrin tetramers $(\mathrm{Sp}-\mathrm{T})$, and the high molecular weight complexes (HMW), but only a small amount of spectrin dimers (Sp-D) $(5 \pm 2 \%$, mean \pm SD of 12 determinations). In contrast, the extract of HPP erythrocytes contains large amounts of $\mathrm{Sp}-\mathrm{D}(34 \pm 4 \%$, for patient D.B., eight determinations; $38 \pm 2 \%$ for patient N.E., six determinations) with a concomitant decrease of Sp-T. To a lesser extent, Sp-D enrichment was present in erythrocytes from both asymptomatic

FIGURE 3 Nondenaturing agarose-polyacrylamide gel electrophorograms and densitometric tracings of spectrin extracts $\left(0^{\circ} \mathrm{C}\right.$, overnight) from normal individuals, HPP patients, and asymptomatic mothers. The positions of HMW, Sp-O, Sp-T, and Sp-D are indicated. 
A
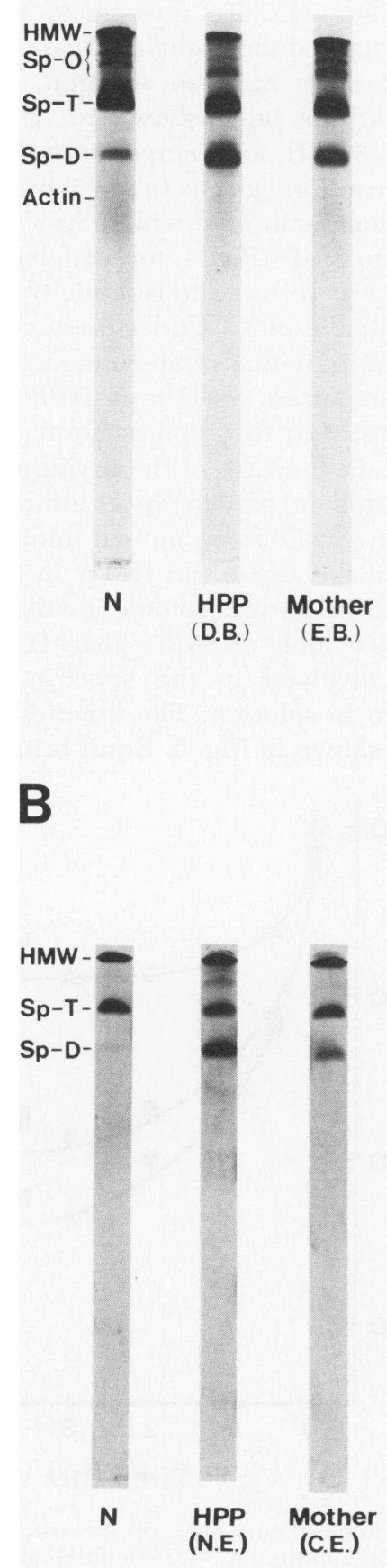

$\mathbf{N}$
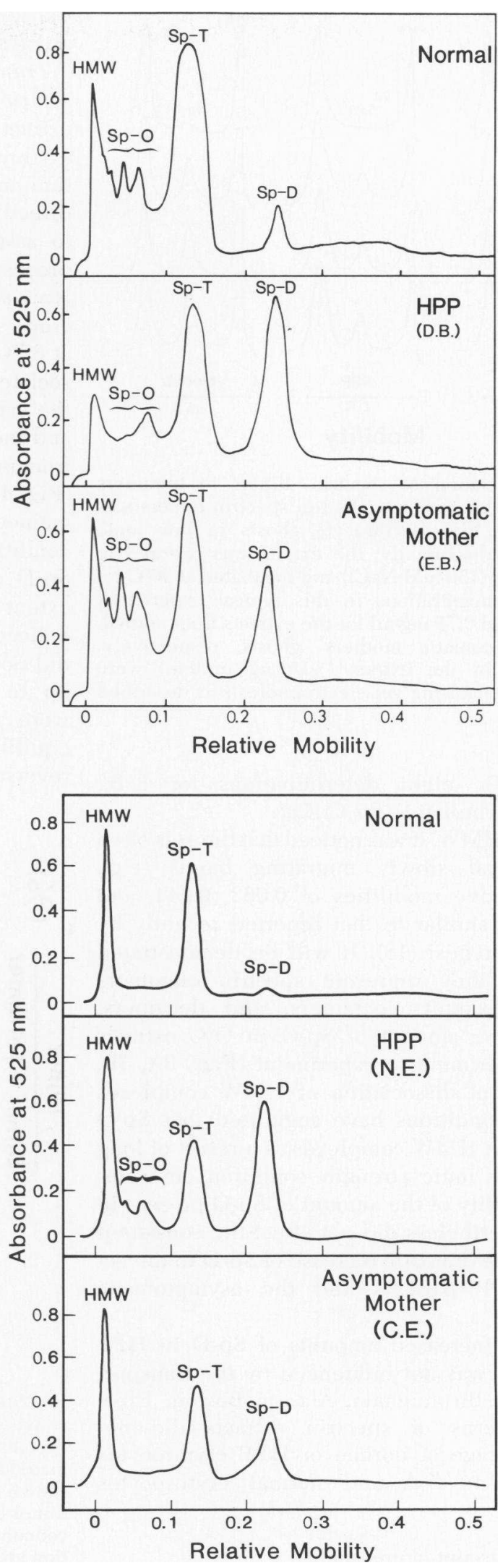


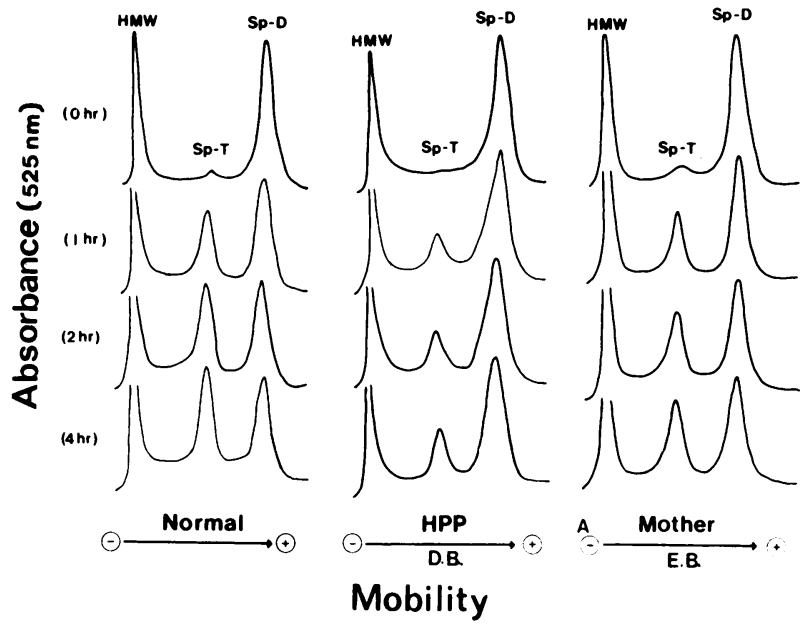

Figure 4 Reassociation of spectrin dimers to tetramers in solution. Crude spectrin enriched in spectrin dimers was extracted at $37^{\circ} \mathrm{C}$ from erythrocyte ghosts in low ionic strength buffer. Subsequently, the extract was restored to isotonic conditions $(150 \mathrm{mM} \mathrm{NaCl})$ and incubated at $30^{\circ} \mathrm{C}$ for 0-4 h. Protein concentrations in this typical experiment were $0.77,0.76$, and $0.75 \mathrm{mg} / \mathrm{ml}$ for the extracts from normal, HPP, and asymptomatic mothers' ghosts, respectively. Spectrin species in the extract $(\sim 15 \mu \mathrm{g}$ protein) were analyzed by nondenaturing gel electrophoresis as described in Fig. 3.

mothers $(20 \pm 2 \%$, eight determinations for E.B., $22 \%$, single determination for C.E.).

In addition to HMW, it was noticed that the gels often contained several slowly migrating bands, e.g., bands with relative mobilities of $0.063,0.044$, and 0.029 (Fig. 3A), similar to that reported recently by Morrow and Marchesi (18). It will be demonstrated elsewhere that they represent spectrin oligomers (Sp-O), i.e., hexamers, octamers, and decamers, respectively. ${ }^{2}$ The amount of $\mathrm{Sp}-\mathrm{O}$ in $\mathrm{O}^{\circ} \mathrm{C}$ extracts varied from experiment to experiment (Figs. 3A, 3B, and 6). Studies of dissociation of HMW complexes under various conditions have suggested that $\mathrm{Sp}-\mathrm{O}$ was derived from HMW complexes as a result of long exposure to low ionic strength conditions in solution. The variability of the amount of $\mathrm{Sp}-\mathrm{O}$ present in the extracts nevertheless did not affect the consistent observation of the dramatic increase of Sp-D in the extracts from HPP patients and the asymptomatic mothers.

The result of increased amounts of Sp-D in HPP spectrin extracts was not influenced by the transport of samples from Birmingham, Ala., to Boston. Electrophoretic patterns of spectrin extracts did not change after storage of normal or HPP erythrocytes at $4^{\circ} \mathrm{C}$ for up to $5 \mathrm{~d}$, and normal erythrocytes

\footnotetext{
${ }^{2}$ Liu et al. Manuscript in preparation.
}

transported in the same manner gave identical results as freshly drawn erythrocytes.

Transformation of spectrin dimers to tetramers in solution. The increase of $\mathrm{Sp}-\mathrm{D}$ to $\mathrm{Sp}-\mathrm{T}$ ratio in the extracts from HPP and the asymptomatic mothers' erythrocytes suggests a defect of spectrin self-association in these cells. To investigate this further, we directly examined the ability of Sp-D from these cells to associate into $\mathrm{Sp}-\mathrm{T}$ in solution, an equilibrium process that has been shown to be influenced by ionic strength, $\mathrm{pH}$, and temperature (5). We extracted crude spectrin from ghosts in low ionic strength buffer at $37^{\circ} \mathrm{C}$, a temperature at which $\mathrm{Sp}-\mathrm{T}$ was mostly dissociated into Sp-D (Fig. 4, top panels). Subsequently, the extract was restored to isotonicity $(150 \mathrm{mM} \mathrm{NaCl})$ and incubated at $30^{\circ} \mathrm{C}$. Under these conditions, Sp-D from normal individuals transformed gradually to $\mathrm{Sp}-\mathrm{T}$ (Fig. 4). In contrast, Sp-D from HPP erythrocytes remained mostly in the dimeric form under the same conditions. In the case of the asymptomatic mothers, $\mathrm{Sp}-\mathrm{D}$ reverted in part to $\mathrm{Sp}-\mathrm{T}$, although to a lesser extent than Sp-D from normal individuals. It was noticed that the amount of $\mathrm{HMW}$ in the $37^{\circ} \mathrm{C}$ extract did not change during isotonic incubation at $30^{\circ} \mathrm{C}$ for up to $4 \mathrm{~h}$, which suggests that HMW complexes were not involved in the spectrin dimer-tetramer equilibrium in solution. The kinetics of the spectrin reversal is shown in Fig. 5. Equilibrium of the dimer-

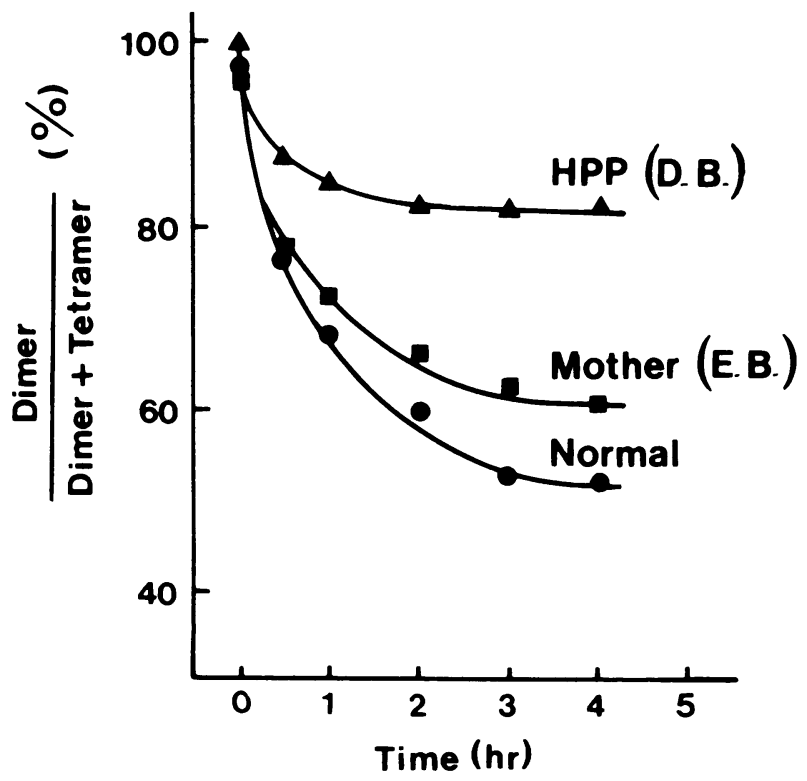

Figure 5 Time-dependence of spectrin dimer-to-tetramer conversion in solution at $30^{\circ} \mathrm{C}$. Relative amounts of spectrin species in the extract during isotonic incubation were estimated from densitometric tracings of nondenaturing gels as shown in Fig. 4. The association constants $\left(K_{\mathrm{a}}\right)$ for spectrin dimer-dimer binding were calculated from the equilibrium concentrations of $\mathrm{Sp}-\mathrm{T}$ and $\mathrm{Sp}-\mathrm{D}$ after $4 \mathrm{~h}$ of isotonic incubation and summarized in Table $\mathrm{I}$. 
TABLE I

Equilibrium Constants of Spectrin Dimer-Dimer Association in Solution*

\begin{tabular}{lcc}
\hline & $K_{\mathrm{a}}$ & $\begin{array}{c}\text { Number of } \\
\text { determinations }\end{array}$ \\
\hline Normal & $10^{5} \mathrm{M}^{-1}$ & \\
HPP (D.B.) & $7 \pm 2$ & 12 \\
Mother (E.B.) & $1.5 \pm 0.5$ & 5 \\
HPP (N.E.) & $4 \pm 1$ & 5 \\
Mother (C.E.) & $1.5 \pm 0.5$ & 3 \\
\hline
\end{tabular}

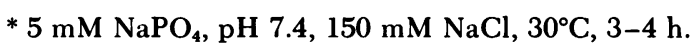

tetramer transformation was achieved after $3-4 \mathrm{~h}$ incubation. On the basis of the equilibrium concentrations of Sp-D and $\mathrm{Sp}$ - $\mathrm{T}$ in the extracts after $4 \mathrm{~h}$ of isotonic incubation at $30^{\circ} \mathrm{C}$ (Fig. 5), the association constants $\left(K_{\mathrm{a}}\right)$ of spectrin dimer-dimer interaction in solution were estimated and summarized in Table $I$. These association constants were independent of the protein concentration used in our studies $(0.4-0.8$ $\mathrm{mg} / \mathrm{ml})$.
Spectrin dimer $\rightleftharpoons$ tetramer transformation in the membrane. To study spectrin dimer-dimer association under physiological conditions (i.e., a spectrin concentration of $\sim 230 \mathrm{mg} / \mathrm{ml}(19)$ at $\left.37^{\circ} \mathrm{C}\right)$, we further compared the spectrin transformation in normal and HPP membranes in situ. This was done by incubating ghosts under hypotonic conditions, which has been shown previously to transform $\mathrm{Sp}-\mathrm{T}$ in part into $\mathrm{Sp}-\mathrm{D}$ in normal ghosts (7). Subsequently, the ability of Sp-D to reverse to $\mathrm{Sp}-\mathrm{T}$ was tested by reincubation of the ghosts under isotonic conditions. The equilibrium concentrations of $\mathrm{Sp}-\mathrm{T}$ and $\mathrm{Sp}-\mathrm{D}$ were measured from $0^{\circ} \mathrm{C}$ extracts derived from these incubated ghosts. When ghosts from normal erythrocytes, HPP (D.B.) erythrocytes, and erythrocytes of the asymptomatic mother (E.B.) were incubated hypotonically in Na phosphate buffer $(5 \mathrm{mM}, \mathrm{pH} 7.4)$ containing $10 \mathrm{mM}$ $\mathrm{NaCl}$ at $37^{\circ} \mathrm{C}$ for $20 \mathrm{~min}$, the amount of Sp-T decreased while the amount of $\mathrm{Sp}-\mathrm{D}$ increased proportionately (Fig. 6, top and middle panels). Upon a subsequent restoration of isotonicity and incubation of ghosts at $37^{\circ} \mathrm{C}, \mathrm{Sp}-\mathrm{D}$ in normal ghosts reassociated back to Sp-T. In contrast, Sp-D in HPP and in the asymptomatic mother's erythrocyte ghosts reversed only par-

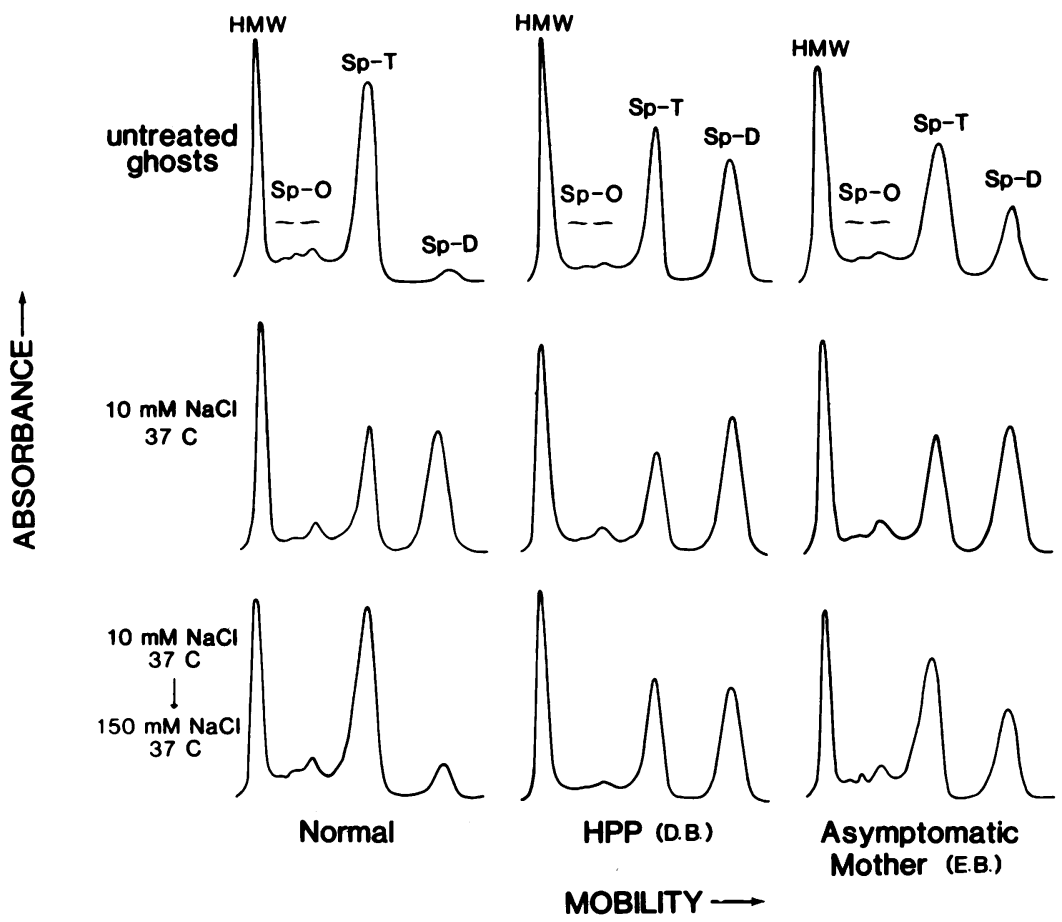

Figure 6 Spectrin tetramer $\rightleftharpoons$ dimer transformation in the membrane. Ghosts were incubated in $5 \mathrm{mM} \mathrm{NaPO}$ buffer $\left(\mathrm{pH} 7.4\right.$ ) containing $10 \mathrm{mM} \mathrm{NaCl}$ at $37^{\circ} \mathrm{C}$ for $30 \mathrm{~min}$ to initiate $\mathrm{Sp}-\mathrm{T} \rightarrow \mathrm{Sp}-\mathrm{D}$ transformation. Subsequently, a portion of the ghosts was reincubated in isotonic buffer containing $150 \mathrm{mM} \mathrm{NaCl}$ at $37^{\circ} \mathrm{C}$ for $30 \mathrm{~min}$ to reverse the transformation. After the incubation, ghosts were washed and extracted overnight with low ionic-strength buffer at $0-4^{\circ} \mathrm{C}$. Spectrin species in the extracts from untreated ghosts (top panels), hypotonic buffer incubated ghosts (middle panels), and isotonic buffer reincubated ghosts (bottom panels) were analyzed by nondenaturing gel electrophoresis and densitometry. 
TABLE II

Equilibrium Constants of Spectrin Dimer-Dimer Association in the Membrane*

\begin{tabular}{lrr}
\hline \multicolumn{1}{c}{$\mathrm{K}_{\mathrm{a}}$} & $\begin{array}{c}\text { Number of } \\
\text { determinations }\end{array}$ \\
\hline Normal & $M^{-1}$ & \\
HPP (D.B.) & $(5 \pm 2) \times 10^{5}$ & 18 \\
Mother (E.B.) & $(2 \pm 1) \times 10^{3}$ & 8 \\
HPP (N.E.) & $(2 \pm 1) \times 10^{4}$ & 8 \\
Mother (C.E.) & $(1.5 \pm 0.5) \times 10^{3}$ & 6 \\
\hline
\end{tabular}

* Data calculated from equilibrium concentrations of $\mathrm{Sp}-\mathrm{T}$ and Sp-D of untreated ghosts (e.g., Fig. 6, top panels) or isotonic-buffer-reincubated ghosts (e.g., Fig. 6, bottom panels).

tially (Fig. 6, bottom panels) and reached approximately the same $\mathrm{Sp}$-D to $\mathrm{Sp}-\mathrm{T}$ ratio as in the original untreated ghosts. Prolonged incubation of HPP ghosts up to $1 \mathrm{hr}$ did not reverse further. The amount of HMW and Sp-O did not change during the spectrin transformation in the membrane, which suggests that HMW and $\mathrm{Sp}-\mathrm{O}$ probably were not involved in the transformation. On the assumption that spectrin concentration in normal and HPP ghosts is $\sim 230 \mathrm{mg} / \mathrm{ml}$ (19), the association constants of spectrin dimer-dimer binding in the membrane at physiological conditions were estimated and summarized in Table II. Association constants of spectrin in the membrane of HPP patient (N.E.) and her asymptomatic mother (C.E.) were derived similarly and included in Table II.

\section{DISCUSSION}

In the present study, we have detected defective selfassociation of HPP spectrin as manifested by $(a)$ increase of $\mathrm{Sp}-\mathrm{D}$ to $\mathrm{Sp}-\mathrm{T}$ ratio in the crude spectrin extracted at $0^{\circ} \mathrm{C}$ (Fig. 3), (b) failure of Sp-D to reassociate into $\mathrm{Sp}-\mathrm{T}$ in solution (Figs. 4 and 5 ), and (c) failure of $\mathrm{Sp}-\mathrm{D}$ to reassociate into $\mathrm{Sp}-\mathrm{T}$ in the membrane (Fig. 6). These abnormalities were associated with mechanical instability of HPP membrane skeletons (Fig. 1), presumably owing to the reduced ability of spectrin to crosslink other skeletal components.

Interestingly, the asymptomatic mothers of HPP patients, who are hematologically normal, with normal erythrocyte morphology and normal thermal stability of erythrocytes, nevertheless exhibited a moderate decrease of membrane skeletal stability, a moderate increase in the amount of Sp-D in $0^{\circ} \mathrm{C}$-extracts, and moderately decreased association constants for spectrin in solution and in the membrane. These data strongly suggest that the asymptomatic mothers are HPP carriers, presumably heterozygotes for the HPP gene. It should be noted that whenever the sample from
HPP patient or carrier was studied, a normal sample was always run parallel in the experiments as control. The differences of the experimental data were highly significant, with no overlap among the individual groups investigated.

Studies of patients with elevated reticulocyte counts and patients with other hemolytic anemias such as hereditary spherocytosis (three patients), sickle cell anemia (four patients), $\beta$-thalassemia (five patients), and hereditary elliptocytosis (13 patients), revealed that most of them had normal membrane skeletal stability and spectrin dimer-tetramer equilibrium, except for a subpopulation of patients with hereditary elliptocytosis. ${ }^{2}$ This subpopulation of hereditary elliptocytosis patients exhibited an altered spectrin dimer-tetramer equilibrium and mechanical instability of their membrane skeletons. It has been reported that neonatal erythrocytes from some patients with hereditary elliptocytosis had poikilocytic and microcytic morphology and were thermally unstable (20). The two unrelated HPP patients in our study were not related with neonatal elliptocytosis, however, since they were 3 and $9 \mathrm{yr}$ old, respectively, and none of their family members exhibited elliptocytosis.

The effect of spectrin transformation on skeleton stability can also be reproduced in normal erythrocyte ghosts. When $\mathrm{Sp}$ - T in normal erythrocyte membranes were partially transformed to Sp-D by $37^{\circ} \mathrm{C}$ incubation of ghosts under hypotonic conditions, the resulting membrane skeletons were mechanically unstable (7), resembling membrane skeletons of untreated HPP erythrocytes. But reincubation of normal erythrocyte ghosts under isotonic conditions corrected the abnormalities of spectrin dimer-tetramer ratio and membrane skeleton stability.

The transformation of spectrin does not involve regulatory proteins (5) and could be directly assessed in crude spectrin extracts without purification (Fig. 4). The presence of actin and HMW in the extract did not affect the $\mathrm{Sp}-\mathrm{D}$ to $\mathrm{Sp}-\mathrm{T}$ transformation. The association constant $\left(K_{\mathrm{a}}\right)$ or normal spectrin derived from the crude extract at $30^{\circ} \mathrm{C}$ in solution was $\left(K_{\mathrm{a}}=[7 \pm 2]\right.$ $\left.\times 10^{5} \mathrm{M}^{-1}\right)$, which is compatible with that derived from purified spectrin $\left(K_{\mathrm{a}}=1 \times 10^{\mathrm{6}} \mathrm{M}^{-1}\right)(5)$. In contrast to normal spectrin, the $K_{\mathrm{a}}$ of HPP spectrin in solution was markedly decreased, i.e., $(1.5 \pm 0.5) \times 10^{5} \mathrm{M}^{-1}$.

Furthermore, we have estimated the value of $K_{\mathrm{a}}$ of spectrin dimer-dimer association in the membrane in $s i t u$, assuming that spectrin concentration in the membrane is $\sim 230 \mathrm{mg} / \mathrm{ml}$ (19), and that $\mathrm{HMW}$ is not involved in $\mathrm{Sp}-\mathrm{D} \rightleftharpoons \mathrm{Sp}-\mathrm{T}$ equilibrium. Striking differences of $K_{\mathrm{a}}$ were evident in the membranes derived from normal individuals, HPP patients, and HPP carriers (Table II). The finding of the abnormality of HPP spectrin in the membrane is complementary to 
that in solution. Whereas the latter establishes that the defect resides intrinsically in spectrin molecules, the former confirms that the defect exists under physiological conditions, where spectrin is membranebound and is in high local concentration.

The defect of spectrin dimer-dimer association in HPP could result from an amino-acid substitution near the contact region or from altered posttranslational modification, such as the state of phosphorylation, proteolytic damage, methylation, or acetylation of $\mathrm{N}$-terminal blockade. To date, no evidence indicates that spectrin phosphorylation is involved in dimertetramer transformation in normal erythrocytes, either in solution (5) or in the membrane (7). Although other posttranslational modifications can not be excluded at the present time, we favor the possibility of an amino acid substitution in HPP spectrin. A detailed peptide analysis is currently being undertaken in our laboratory.

\section{ACKNOWLEDGMENTS}

We thank P. Y. Aileen Liu, James Monroe, and Nelson Chu for technical assistance.

This research was supported by National Institutes of Health grants F32-HL05557 and HL15157.

\section{REFERENCES}

1. Zarkowsky, H. S., N. Mohandas, C. S. Speaker, and S. B. Shohet. 1975. A congenital hemolytic anemia with thermal sensitivity of the erythrocyte membrane. $\mathrm{Br} . J$. Haematol. 29: 537-543.

2. Chang, K., J. R. Williamson, and H. S. Zarkowsky. 1979. Effect of heat on the circular dichroism of spectrin in hereditary pyropoikilocytosis. J. Clin. Invest. 64: 326-328.

3. Walter, T., W. Mentzer, A. Greenquist, S. Schrier, and N. Mohandas. 1977. RBC membrane abnormalities in hereditary pyropoikilocytosis. Blood. 50(Suppl. 1): 98. (Abstr.)

4. Palek, J., S. C. Liu, P. A. Liu, J. Prchal, and R. P. Castleberry. 1981. Altered assembly of spectrin in red cell membranes in hereditary pyropoikilocytosis. Blood. 57: $130-139$.

5. Ungewickell, E., and W. Gratzer. 1978. Self-association of human spectrin. A thermodynamic and kinetic study. Eur. J. Biochem. 88: 379-385.

6. Ji, T. H., D. J. Kiehm, and C. R. Middaugh. 1980. Presence of spectrin tetramer on erythrocyte membrane. J. Biol. Chem. 255: 2990-2993.

7. Liu, S. C., and J. Palek. 1980. Spectrin tetramer-dimer equilibrium and the stability of erythrocyte membrane skeletons. Nature (Lond.). 285: 586-588.

8. Shotton, D. M., B. E. Burke, and D. Branton. 1979. The molecular structure of human erythrocyte spectrin. Biophysical and electron microscopic studies. J. Mol. Biol. 131: 303-329.

9. Ungewickell, E., P. M. Bennet., R. Calvert, V. Ohanian, and W. Gratzer. 1979. In vitro formation of a complex between cytoskeletal proteins of the human erythrocyte. Nature (Lond.). 280: 811-814.

10. Tyler, J. M., W. R. Hargreaves, and D. Branton. 1979 Purification of two spectrin binding proteins: biomedical and electron microscopical evidence for site specific reassociation between spectrin and band 2.1 and 4.1. Proc. Natl. Acad. Sci. U. S. A. 76: 5192-5196.

11. Cohen, C. M., and S. F. Foley. 1980. Spectrin-dependent and -independent as sociation of $\mathrm{F}$-actin with the erythrocyte membrane. J. Cell Biol. 86: 694-698.

12. Brenner, S. L., and E. D. Korn. 1979. Spectrin actin interaction. Phosphorylated and dephosphorylated spectrin tetramer crosslink F-actin. J. Biol. Chem. 254: 8620-8627.

13. Fowler, V., and D. L. Taylor. 1980. Spectrin plus band 4.1 crosslink actin. Regulation by micromolar calcium. J. Cell Biol. 85: 361-375.

14. Sheetz, M. P. 1979. DNase I-dependent dissociation of erythrocyte cytoskeletons. J. Cell Biol. 81: 266-270.

15. Dodge, J. T., C. Mitchell, and D. J. Hanahan. 1963. The preparation and chemical characteristics of hemoglobin free ghosts of human erythrocytes. Arch. Biochem. Biophys. 100: 119-130.

16. Fairbanks, G., T. L. Steck, and D. F. H. Wallace. 1971. Electrophoretic analysis of the major polypeptides of the human erythrocyte membrane. Biochemistry. 10: 2606-2617.

17. Liu, S. C., G. Fairbanks, and J. Palek. 1977. Spontaneous, reversible protein crosslinking in the human erythrocyte membrane. Temperature and $\mathrm{pH}$ dependence. Biochemistry. 16: 4066-4074.

18. Morrow, J. S., and V. T. Marchesi, 1981. Self-assembly of spectrin oligomers in vitro: a basis for a dynamic cytoskeleton. J. Cell Biol. 88: 463-468.

19. Lux, S. E. 1979. Spectrin-actin membrane skeleton of normal and abnormal red blood cells. Semin. Hematol. 16: $21-51$.

20. Zarkowsky, H. S. 1979. Heat-induced erythrocyte fragmentation in neonatal elliptocytosis. Br. J. Haematol. 41: 515-518. 